\title{
Revista de Oncología, seis años después
}

La Federación de Sociedades Españolas de Oncología ha pasado los últimos seis años por un contencioso legal originado por una demanda interpuesta por la Editorial ALPE, que la Audiencia Provincial de Madrid ha sentenciado en segunda instancia a favor de la FESEO.

Haciendo un resumen de las razones que han provocado este litigio, comenzó en 1997 cuando la Junta Directiva de la FESEO movida por el deseo de elevar el nivel científico de la Revista de Oncología, inició una serie de gestiones para lograr un reconocimiento a nivel internacional. Durante los doce años anteriores la FESEO mantuvo con la Editorial ALPE un contrato atípico para la edición y distribución de la Revista de Oncología. Fruto de este acuerdo la Editorial ALPE se beneficiaba de importantes ingresos económicos de los cuales la FESEO recibía una pequeña parte destinada en su totalidad a la remuneración del Comité Editorial de la Revista de Oncología. Tras varios intentos de firmar un contrato razonable con la Editorial ALPE se decidió encargar a un prestigioso gabinete de abogados que realizara una oferta pública a las editoriales especializadas en revistas médicas para la selección de la que más estuviese de acuerdo con las aspiraciones acordadas por la FESEO. La FESEO comunicó sus intenciones a la Editorial ALPE con varios meses de antelación y ésta decidió en abril de 1998 poner de manifiesto su intención de participar en el concurso de la nueva revista, aunque posteriormente decidió no presentarse al proceso de selección. Como resultado de este cambio la FESEO firmó un Contrato de colaboración con la Editorial Doyma para la edición y distribución de la Revista de Oncología. Los resultados a lo largo de estos seis años han demostrado un aumento en la calidad científica de la Revista de Oncología y nos ha permitido que sea admitida por los National Institutes of Health para su evaluación y posible inclusión en Medline.

Este cambio, que indudablemente ha sido beneficioso para la Revista de Oncología, le valió a la FESEO una demanda interpuesta por la Editorial ALPE, presentada en mayo de 1999 y en la cual se pedía el cumplimiento del contrato atípico con la FESEO y la indemnización por daños y perjuicios. La FESEO no admitió esta demanda y además de oponerse decidió reconvenir contra ALPE solicitando el pago de la deuda de 18 meses por no haber efectuado los pagos correspondientes a la colaboración del equipo editorial desde julio de 1997 hasta diciembre de 1998. Tras el juicio celebrado en el Juzgado de Primera Instancia se dictó sentencia a favor de la Editorial ALPE condenando a la FESEO después de la peritación correspondiente, a una deuda millonaria. En la misma sentencia se condenaba a Editorial ALPE al pago de 2.700.000 pts, la deuda por los pagos al Comité Editorial. La FESEO decidió recurrir esta sentencia en la Audiencia Provincial de Madrid a través del mismo gabinete de abogados que había gestionado tanto la selección de la nueva editorial para la Revista de Oncología como el juicio originado por la demanda de la Editorial ALPE. La causa defendida por la FESEO en la Audiencia Provincial, basada exclusivamente en la evidencia y línea argumental del primer juicio, logró demostrar que la ruptura del contrato atípico con la Editorial ALPE no supuso abuso de derecho alguno y por tanto no procede a la indemnización de daños y perjuicios. Aunque publicaremos la sentencia en su totalidad en el próximo número de la Revista de Oncología, valga de ejemplo el párrafo final de la misma.

\section{"III Fallamos}

Que estimado el recurso de apelación, interpuesto por el procurador Sr. D. Román Velasco Fernández en representación procesal de FESEO contra la sentencia dictada por el Juzgado de Primera Instancia número 42 de Madrid, en autos de Menor Cuantía número 483-1999, debemos revocar y revocamos la misma y por la presente, se desestima en su totalidad la demanda formulada por la Procuradora Doña Mónica de la Paloma Fente Delgado en nombre y representación de ALPE EDITORES S.A. absolviendo al demandado de las pretensiones contra él deducidas manteniendo el resto de los pronunciamientos y con la imposición de las costas de primera instancia al actor, sin que proceda imponer las de alzada a ninguna de las partes."

Además de detenerse los expedientes de embargo iniciados por ALPE contra la FESEO, la Editorial ALPE debe de hacer frente al pago de la sentencia de tribunal de Primera Instancia con los intereses correspondientes. 
Los hechos han dado la razón a la FESEO y demostrado que la gestión iniciada por la Junta Directiva de la FESEO presidida por el Dr. Enrique Fuster Diana para el cambio editorial en la Revista de Oncología estuvo llevada por el solo ánimo de elevar la calidad de la revista y mejorar la situación de la FESEO y que esta gestión se realizó en el marco de la legalidad. Así mismo se ha demostrado que la línea de defensa que siguió la FESEO era la adecuada como ha reconocido la Audiencia Provincial,

El camino que hemos recorrido hasta esta sentencia ha sido largo y en muchos momentos difícil. Quiero expresar mi agradecimiento en nombre de la Junta Directiva de la FESEO a los Presidentes que a lo largo de este tiempo han llevado la gestión de la FESEO y ayudado a llevar a buen puerto este proceso judicial:
Dr. Enrique Fuster, Dr. Gregorio Aragón, Dr. Alberto Biete, y el Dr. Javier Dorta con sus respectivas Juntas Directivas. Así mismo agradecemos a las personas que durante estos años han formado parte del Comité Editorial, por avanzar hacia una mejora en la calidad de la Revista de Oncología. Desde la FESEO continuaremos, tal como lo hemos hecho hasta ahora, promoviendo las actividades Científicas de calidad en Oncología y contribuyendo al aumento progresivo del nivel de la Revista de Oncología

Madrid, Febrero de 2004

Rosario Perona Presidenta de la Federación de Sociedades Españolas de Oncología (FESEO) 